CALEIDOSCOPIO

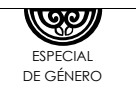

\section{Género y zapatismo de las mujeres indígenas, de Márgara Millán}

JOSÉ ACEVEDO ACOSTA'

Millán, Márgara, Des-ordenando el género /¿Des-centrando la nación? El zapatismo de las mujeres indigenas y sus consecuencias. (2014). UNAM, pp. 356. México.

Desde hace tiempo el tema de género se ha colocado en el centro cultural de estudios y debates en foros nacionales e internacionales. México se ha sumado a estas reflexiones teóricas y políticas desde hace tres décadas, con un nivel de análisis y difusión importantes, y continúa fomentando la igualdad y equidad de género como una tarea necesaria. Es por ese motivo que expondremos algunas de las aproximaciones teóricas, metodológicas y vivenciales escritas por la antropóloga Márgara Millán, como resultado de su investigación doctoral en la comunidad tojolabal de San Miguel Ch'

Profesor-Investigador del Departamento de Filosofía. Universidad Autónoma de Aguascalientes. ib' tik, próxima a San Cristóbal de las Casas, Chiapas, México.

Su tesis doctoral le ocupó siete años, con estancias de meses, entrevistas personales a ancianas, ancianos, muchachas jóvenes y hombres en su etapa juvenil y dirigentes del Ejército Zapatista de Liberación Nacional, de Municipios Autónomos y su nueva expresión de Juntas de Buen Gobierno.

El título de su tesis se publicó como libro apenas en noviembre 2014 por la UNAM, con el sugerente y provocador título de Desordenando el género/¿des-centrando la nación? El zapatismo de las mujeres indígenas y sus consecuencias, que se suma a las miradas teóricas contemporáneas sobre estudios de género, y que nos invita a salir de las universidades para conocer y comparar las visiones teóricas y las manifestaciones vivas y originales con las que se refleja esa cultura en las comunidades indígenas. 
Para ella, los cambios culturales de género se vienen produciendo en diversas naciones, en condiciones distintas, con características particulares en cada caso, y desde hace más de un siglo; de tal modo que ahora sabemos que no hay una sola línea de pensamiento ni es un tema exclusivo de las mujeres pioneras reconocidas como Simone de Beauvoir, Joan Scott, Marcela Lagarde, Patricia Ravelo y muchas otras, por lo que es recomendable comprender cómo se han producido las organizaciones y avances en México entre las mujeres neozapatistas.

La autora, dentro de su obra, menciona que: "El objetivo de este trabajo es resaltar los diálogos a nivel nacional y local que componen este movimiento y que él mismo convoca una vez que entra a la luz pública, visibilizando el lugar y las representaciones de las mujeres indígenas que están en juego. Este libro intenta ofrecer al lector un acercamiento a las distintas dimensiones de este movimiento en cuanto a la participación y representaciones de las mujeres indígenas, y buscar su nexo con la constitución (concepto) de lo que entendemos por Nación" (2014:15).

El primer capítulo da cuenta del contexto zapatista, simultáneamente global, nacional y local del movimiento neozapatista. El segundo resalta los contenidos de género que están presentes en el discurso neozapatista oficial, de sus organizaciones y su vida cotidiana. El tercero recupera la dimensión comunitaria del neozapatismo indígena de base, cómo éste ha ido tomando forma en la comunidad tojolabal de San Miguel Ch' ib' tik. Es aquí donde afloran las tradiciones y las formas sociales de convivencia, la memoria histórica, las estructuras organizativas singulares de los indígenas y las prácticas propias del neozapatismo. El cuarto capítulo define y enfatiza lo que Márgara denomina el reordenamiento o renegociación del orden de género en la vida cotidiana. El último capítulo concluye con el cierre y el balance de las demandas enunciadas por las mujeres indígenas, resaltando la posibilidad, que se manifiesta en esa comunidad, de ser tomada como parte del continente de la nación mexicana. El trabajo de campo se realizó en San Miguel Ch'ib'tik, entre 1997 y 2006.

En el capítulo primero, resulta novedoso identificar cómo las mujeres en las comunidades indígenas van asumiendo tareas de responsabilidad social, en cooperativas, como promotoras de salud y teniendo negociaciones directas con autoridades de gobierno; las mujeres van ganando experiencia y modificando su posición a favor de las Juntas de Buen Gobierno. 
Así, además de adherirse a las demandas comunitarias, étnicas y éticas del neozapatismo, le dan forma a las demandas de género que serán recogidas en la Ley Revolucionaria de Mujeres del EZLN. Por ello, añade Márgara, el neozapatismo puede ser leído y visto como un movimiento que interpela las prácticas clientelares en relación con el Estado, como la estrechez de la ciudadanía democrática electoral, incluyendo la "cuestión de las mujeres".

No existe un modelo de "comunidad indígena" sino una diversidad. "Las comunidades indígenas zapatistas son un terreno heterogéneo donde se producen formas diversas de reactualización de lo político, del orden comunitario y de la igualdad de género" (58). Las organizaciones de mujeres indígenas combinaron su trabajo con la Coordinadora Diocesana de Mujeres para mejorar sus condiciones de vida, interpelando la palabra de Dios desde la perspectiva de los derechos de las mujeres; se coaligaron con organizaciones católicas de los Altos de Chiapas y contaron con la experiencia y apoyo de organizaciones guatemaltecas, como Mamá Maquín, Flores Unidas y Madre Tierra, que impulsaron los esfuerzos de las mujeres neozapatistas en la década de los ochenta.

El capítulo dos presenta los nuevos horizontes de visibilización de las mujeres indígenas (2014:63). Se trata de un razonado discurso en el suelo de vida de mujeres indígenas desde antes del levantamiento zapatista de enero 1994 y los años siguientes, como se puede constatar por los diálogos, fuentes documentales, debates y avances teóricos en el proceso de la historia y la lucha neozapatista. Se parte de los referentes legislativos nacional, estatal y de ordenamientos jurídicos eclesiásticos, por un lado; por el otro, del diálogo intelectual e histórico circunstancial producido entre intelectuales urbanos, chilangos, y las concepciones expuestas por las mujeres indígenas organizadas, y terciando en la discusión la palabra y ordenamiento del debate propiciado por Márgara.

Márgara incluye en su libro estampas fuertes con intervenciones de mujeres indígenas neozapatistas, que orientan el nuevo imaginario social. Primero, la Comandante Ramona en los Diálogos de San Cristóbal (1995). Ella es la primera mujer que se da a conocer públicamente al lado de Marcos y de los 19 delegados zapatistas que participaron en las Jornadas por la Paz y la Reconciliación, en San Cristóbal de las Casas, en febrero de 1994. Su mensaje en la Universidad Nacional Autónoma de México, corazón de la intelligentzia, desborda y moviliza las conciencias ciudadanas; 
no entendemos su lengua tzotzil, pero sí el sentido profundo de su mensaje; segundo, la muerte de 32 mujeres en Chenalhó, en diciembre de 1997; tercera, la Comandante Esther en el Congreso de la Unión, 28 de marzo de 2001. La Comandante Esther devela sus identidades: ser mujer y ser indígena, ser zapatista y su deseo de ser mexicana; nombra la manera en que el Estado con sus leyes, la desigualdad social, con la marginación y la exclusión, el racismo, con humillación y la falta de reconocimiento en el ordenamiento de género, con la disparidad entre hombres y mujeres en las decisiones y las costumbres comunitarias, conforma una sola cultura, dominante, que la excluye como ser humano, por ser mujer, indígena, pobre y rebelde". (2014: 112) Esther: "queremos que sea reconocida nuestra forma de vestir, de hablar, de gobernar, de organizar, de rezar, de curar, nuestra forma de trabajar en colectivos, de respetar la tierra y de entender la vida, que es la naturaleza, que somos parte de ella". (2014: 112)

El debate teórico se produce en el apartado que Márgara denomina 'Sobre la 'agenda' de las mujeres: derechos reproductivos y contenidos del 'género' como concepto, una polémica". Se discute sobre el aborto, su despenalización, las legislaciones sobre el mismo, y se enriquece con los planteamientos de antropólogas, feministas, periodistas, intelectuales y las voces del neozapatismo, ello conduce la discusión a descubrir en la visibilización del fenómeno neozapatista una experiencia y un avance cultural real que evita dejarse encasillar por los criterios "urbanos" y "hegemónicos" de la intelectualidad, al propio tiempo que solicita: "Hay que oírlas con cuidado, traducirlas, dejarnos interpelar por su horizonte epistémico y emancipatorio". (2014: 132)

En el apartado "Género y nación" (2014:98), Nira Yuval-Davies encuentra al menos tres intersecciones entre mujeres y nacionalismo: a) Mujeres como reproductoras físicas de las naciones; b) Mujeres como reproductoras de los límites de las naciones/comunidades/etnias, a través de las restricciones exogámicas: 1) Mujeres como guardianes/transmisoras activas/productoras de las culturas nacionales/comunitarias étnicas; 2) Mujeres como significantes de las diferencias nacionales/comunitarias/étnicas; y c) Mujeres como participantes activas en las luchas nacionales/comunitarias/étnicas. También encontramos esa intersección con personajes de mujeres en la historia nacional: Malitzin, Tía Marina, la Virgen de Guadalupe, Josefa Ortiz, las Adelitas, como representantes de una cul- 
tura oficial nacional, que se expropia, se reprime y se explota, todo ello justificado en las lecturas oficiales de la liberación-dominación de las mujeres en distintas épocas históricas (2014:99).

Por su parte, el neozapatismo como movimiento social ingresa en la arena política priorizando lo que podríamos llamar una "agenda de género", que está constantemente presente en los escenarios donde encontramos al zapatismo/neozapatismo y le otorga a las mujeres indígenas un símbolo de la nación por venir. Así, las vemos hablando fuerte, reclamando los derechos de paridad y equidad al Estado/mal gobierno y al varón/usos y costumbres, enfrentándose con palos a los soldados/represión del masculino Estado, leyendo apropiadamente en castellano en el Congreso de la Unión... Las mujeres indígenas defienden su mexicanidad, diciendo cómo quieren ser inscritas en la nación, pero también definen su indianidad, dentro y fuera de sus comunidades. A ello se suman las interesantes entrevistas a jóvenes indígenas. 1) Promotora social y militante zapatista Adriana (16.07.1999); 2) La maestra militante del movimiento del magisterio de Chiapas Jazmín (17.07.1999), feminista declarada, participa como asesora en el proyecto educativo del EZLN; 3). Delfina es una mujer tojolabal, salió de su comunidad hace años, colabora como educadora y traductora de su lengua al español; ha padecido en carne propia el poder de los varones.

En respuesta a una nota publicada en La Jornada, de Rosa Rojas (07.09.2005), “El EZLN expulsó de sus zonas de influencia a grupos feministas" (2024:146), la misma dirigencia responde de inmediato en los siguientes términos: "En efecto, con ustedes $[\ldots]$ nuestra estructura político-militar cometió, en años pasados, una serie de arbitrariedades e injusticias [...| Por ello les pedimos ahora disculpas públicas... Reconocimos así que la presencia de nuestros mandos político-militares no siempre era benéfica para el desarrollo de la resistencia... Por eso fue que se crearon los Caracoles y las Juntas de Buen Gobierno... Todo el trabajo en comunidades incluyendo el muy loable de promoción de los derechos de la mujer, se ve ahora y desde hace dos años directamente con las Juntas de Buen gobierno..." (2014:147).

Las principales fuentes del Zapatismo en la vida social y matrimonial se reciben: 1) de la convivencia de las generaciones jóvenes que se han adherido al movimiento zapatista y, 2) de la contribución recibida de la Diócesis de San Cristóbal de las Casas mediante la Coordinadora Diocesana de Mujeres (CODIMU). 
El principio de igualdad entre mujeres y hombres, entre jóvenes de comunidades zapatistas tojolabales, los lleva a admitir que también la conciencia de hombres y mujeres ancianos, adultos mayores y jóvenes está modificándose, porque la integración de las chicas zapatistas a la organización zapatista se deriva de discusiones y acuerdos en familias y escuela, en la participación de gobierno y en todos los medios comunitarios. Es una decisión individual-familiar-colectiva de posponer el matrimonio porque ellas así lo quieren, porque de otro modo no pueden participar. Aún persiste la autoridad cultural del varón en la vida familiar, pero es un principio que se debate, se incorpora en sus vidas y que va modificando patrones culturales ancestrales, lo que permite una amplia intervención de las jóvenes. Esto hizo posible que en la consulta nacional zapatista participaran 2,500 indígenas, mitad mujeres, mitad hombres, no por decreto, sino por convicción colectiva.

Ahora cobra sentido y concepto el título que Márgara utilizó para su obra: Des-ordenando el género/ ¿des-centrando la nación? El zapatismo de las mujeres indígenas y sus consecuencias, porque el nombre del libro introduce el término des-ordenar como búsqueda de una realidad, como categoría conceptual que encuentra entre catequistas, indígenas de campo, jóvenes varones y mujeres de edad temprana; desordenando, porque las lecciones de la teología convergen con las aspiraciones del zapatismo de Emiliano Zapata y con el zapatismo del EZLN, en cuanto que dialogando, discutiendo y viviendo se van apropiando de un lenguaje que identifica al varón con el Estado, gobierno, dominación, hombres, papás, jóvenes varones de una tradición, y el cambio que comienza a manifestarse, donde comienza a admitirse y a afirmarse la figura femenina, por su trabajo, su colaboración, su toma de conciencia y su firme decisión de no depender más del poder masculino del Estado y del esposo, sino de ir en búsqueda de una identidad nacional al lado con las mujeres, como ejes y entes indispensables para la transformación del gobierno, del poder masculino y de la represión y poderes del Estado.

La contribución de Márgara representa una invitación al estudio y aproximación a esas vidas y a esas voces juveniles. La juventud de Chi' ib' tik sabe y admite que sus vidas están cambiando los valores sociales y culturales de su entorno y comienzan a imaginar que su contribución irá más allá de las fronteras de su comunidad, tan lejos como el pensamiento neozapatista, que es oído, escuchado y seguido más allá de los límites territoriales del país México. 